\section{The efficacy and safety of high-intensity focused ultrasound ablation of benign thyroid nodules}

\author{
Brian H. Lang, Arnold L. H. Wu \\ Department of Surgery, Queen Mary Hospital, University of Hong Kong, Hong Kong, China
}

High-intensity focused ultrasound (HIFU) is a promising form of thermal ablation of benign thyroid nodules, but evidence supporting its use is scarce. The present review evaluated the efficacy and safety of single-session HIFU treatment of benign thyroid nodules. As reported in the literature, the extent of nodule shrinkage following treatment ranged from $48.8 \%$ to $68.8 \%$. Like other forms of ablation, the shrinkage rate was greatest in the first 3-6 months, and the best responders were patients with small $(\leq 10 \mathrm{~mL})$ nodules. Complications were uncommon, but temporary vocal cord palsy occurred in $3 \%-4 \%$ of patients, and was related to the distance between the HIFU beam and the recurrent laryngeal nerve. Despite being safe and efficacious, a larger-scale prospective trial is required.

Keywords: Ultrasonography, interventional; High-intensity focused ultrasound ablation; Hyperthermia, induced; Goiter, nodular; Ablation techniques

\section{Introduction}

Thyroid nodules are common and can be discovered by clinical palpation in $5 \%$ of normal individuals and by high-resolution ultrasonography (US) up to $60 \%$ of the general population [1,2]. However, since most of these nodules (>90\%) are benign and will remain relatively unchanged over time, observation and reassurance are normally recommended [3]. According to recent clinical practice guidelines, surgical resection is only indicated when a nodule becomes large $(\geq 4 \mathrm{~cm})$ or is causing obstructive and/or local pressure symptoms [1-3]. For years, surgical resection has remained the mainstay of treatment for large and/or symptomatic benign thyroid nodules because it is considered safe when done by an experienced surgeon. Nevertheless, surgical resection can lead to complications and is associated with high costs and a need for general anaesthesia. As a result, increasing interest has emerged in developing less invasive, non-surgical procedures for the treatment of large symptomatic benign thyroid nodules $[4,5]$.

To date, a number of less invasive options, including ethanol ablation, laser ablation (LA), microwave ablation, and radiofrequency ablation (RFA) [5-7] have been described. Ethanol ablation has been shown to be effective for thyroid cysts and is recommended for recurrent, benign thyroid cysts $[5,8]$. However, for solid or predominantly solid ( $<30 \%$ cystic area) nodules, thermal ablation techniques such as LA and RFA are generally preferred $[7,9,10]$. Studies have found these thermal techniques not only can result in significant nodule size reduction, but also reduce nodule-related

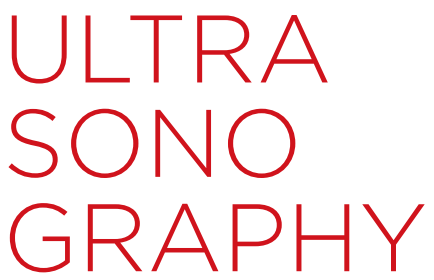

REVIEW ARTICLE

https://doi.org/10.14366/usg.17057 pISSN: 2288-5919 • elSSN: 2288-5943

Ultrasonography 2018;37:89-97

Received: August 26, 2017

Revised: October 7, 2017

Accepted: October 10, 2017

Correspondence to:

Brian H. Lang, MBBS (HK), MS (HK),

FRACS, Department of Surgery,

University of Hong Kong, Pokfulam,

Hong Kong, China

Tel. $+852-22554773$

Fax. +852-28172291

E-mail: blang@hku.hk
This is an Open Access article distributed under the terms of the Creative Commons Attribution NonCommercial License (http://creativecommons.org/ licenses/by-nc/3.0/) which permits unrestricted noncommercial use, distribution, and reproduction in any medium, provided the original work is properly cited.

Copyright (C) 2018 Korean Society of Ultrasound in Medicine (KSUM)

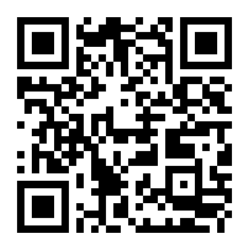

How to cite this article:

Lang BH, Wu ALH. The efficacy and safety of high-intensity focused ultrasound ablation of benign thyroid nodules. Ultrasonography. 2018 Apr;37(2):89-97. 
symptoms in many patients [7,9-12].

High-intensity focused ultrasound (HIFU) is a new thermal ablation technique that is gaining popularity among clinicians [11]. However, relative to other thermal techniques, it has been less well described in the literature. Given the scarcity of the evidence, the aim of this review was to comprehensively evaluate the efficacy and safety of HIFU treatment of benign thyroid nodules.

\section{High-Intensity Focused Ultrasound for Benign Thyroid Nodules}

\section{What is HIFU?}

HIFU is a form of thermal ablation in which energy is delivered in the form of US waves extra-corporeally to a targeted area deep beneath the skin. Since energy can be delivered accurately under US guidance, the risk of damaging or injuring the surrounding tissues is small [13]. During treatment, multiple high-energy US waves are generated and focused at one particular area to induce thermal ablation. Direct damage to biological tissues usually takes two forms: the thermal effect and acoustic cavitation. In the thermal effect, the targeted tissue absorbs the US waves, which causes molecules to vibrate and/or rotate, leading to frictional heat [14]. When the tissue temperature reaches $56^{\circ} \mathrm{C}$ or above for a duration of 1 second, protein denaturation and coagulation necrosis begin [14].

Another form of damage is known as acoustic cavitation, in which microbubbles are formed from the US energy $[15,16]$. The negative pressure caused by the US waves on the tissue withdraws gas from the tissue, causing bubbles to form. These bubbles either oscillate according to the frequency of the US waves or expand gradually and collapse [17].

\section{Other Biological Effects of HIFU}

Apart from the direct thermal and cavitation effects, when tissues are exposed to lower-energy US, some cells stop proliferating and undergo some subtle cellular changes. For example, the cellular membrane becomes more permeable, leading to changes in the intracellular environment and intracellular electrolyte balance [18]. Other modifications include changes in intracellular proteins in locations where DNA synthesis and polymerization are controlled [13]. These changes cause slow cell death and, in turn, directly stimulate natural killer cells, CD8 ${ }^{+} T$ cells, and dendritic cells. The resultant activity of these cells facilitates the detection and destruction of any remaining tumor cells both locally and systemically. Lastly, the thermal treatment can modify the vasculature of the tumor. The permeability of the tumor vasculature is increased [13]. Overall, lowpower HIFU ablation can sensitize tumors to the effects of radiation and chemotherapy, as well as enhancing local drug and gene delivery to tumors, and has an immune-stimulatory capacity [19].

\section{Nodule Selection and Treatment Indications}

In most instances, any thyroid nodule that has been confirmed to be benign on at least one occasion by fine-needle aspiration cytology or core needle biopsy is suitable for HIFU ablation. The ablation of follicular neoplasms or primary thyroid cancers is not recommended [20]. Some groups prefer to obtain two consecutive benign fineneedle aspiration cytology results or one benign core needle biopsy before proceeding to ablation $[21,22]$. However, in our view, this may not be necessary, because the likelihood of malignancy in a nodule without suspicious clinical and US features and with benign cytology (i.e., Bethesda class II) is very small $(<1 \%-2 \%)$ [2]. Table 1 compares the inclusion and exclusion criteria between different HIFU studies. One exclusion criterion worth highlighting is whether the patient must be able to extend his or her neck during treatment, because inadequate neck exposure or extension makes the placement of the treatment head on the patient's neck difficult. The distance between the center of the nodule and the skin is also important, because nodules that are too near $(\leq 5 \mathrm{~mm})$ or too deep $(\geq 3 \mathrm{~cm})$ from the skin render the treatment unsafe and not feasible. Skin burns can occur when treating lesions close to the skin, while treatment is less effective for lesions located too deep.

In terms of treatment indications, one important consideration is that the nodule should be causing some physical symptoms or concerns, because most thyroid nodules do not cause symptoms and can be left untreated. In our practice, patient preference is considered a relative indication, because surgical resection remains the treatment of choice for symptomatic or rapidly growing benign nodules.

To allow for the more objective follow-up assessment of symptoms, using a 0 - to $10-\mathrm{cm}$ visual analog score is recommended before and after treatment. Cosmetic concerns can often be assessed by a 1-4 grading score (1, no palpable nodule; 2 , palpable but not visible nodule; 3 , visible nodule on swallowing; 4 , readily visible nodule) [22].

\section{Technique and Equipment}

Patients undergoing HIFU ablation are required to fast for at least 4-6 hours before the procedure because the administration of intravenous sedation and analgesia may cause nausea or vomiting during or after the procedure. Prior to treatment, a fine-bore cannula (20F or $22 \mathrm{~F}$ ) is inserted to allow easy venous access for drug administration. For sedation and analgesia, intravenous pethidine (50-100 mg) (an opioid pain medication) and diazepam (5-10 mg) (a short-acting benzodiazepine) are administered together 5-10 minutes before the procedure $[23,24]$. Although most patients feel some pain and discomfort in the ablation area during treatment because the US energy needs to propagate through the skin, the pain is usually tolerable, and in our experience, it is unusual to have the procedure stopped prematurely because of pain. Some patients 
may also experience pain radiating to the back of the neck or the shoulder area, which is believed to be related to the stimulation of nerve plexuses behind the thyroid gland by the US energy. Interestingly, in our experience, using a deep cervical nerve block did not seem to reduce this specific complaint, whereas lowering the ablation power was a more effective method of reducing that type of pain.

In terms of the actual procedure, patients are positioned in a supine position with their neck slightly extended by placing a pillow behind the shoulders. After adequate neck exposure, the treatment is carried out with an US-guided HIFU device (EchoPulse, Theraclion, Paris, France). This commercially-available device is essentially a US- guided HIFU machine with a 3-MHz extracorporeal probe, and it comprises four parts: an energy generator, a treatment probe, a skin cooling device, and a touch-screen monitor for control $[23,24]$. The treatment probe operates on two independent US systems, one for real-time imaging guidance and the other as a HIFU transducer. The imaging system contains 128 elements arranged in a linear array and emits frequencies of $7.5 \mathrm{MHz}$. The HIFU transducer system contains a single element, measuring $60 \mathrm{~mm}$ in diameter. It is capable of emitting frequencies of $3 \mathrm{MHz}$ of pulses up to $125 \mathrm{~W}$ of maximum acoustic power, with larger and deeper targets receiving higher power. The imaging system is placed right in the middle of the probe, meaning that the focal point of treatment is always at the

Table 1. A comparison of inclusion and exclusion criteria for HIFU ablation of benign thyroid nodules

\begin{tabular}{|c|c|c|}
\hline Study & Inclusion criteria & Exclusion criteria \\
\hline \multirow[t]{3}{*}{ Esnault et al. (2011) [25] } & At least 2 thyroid nodules, with 1 needing surgery & $\begin{array}{l}\text { Suspicion of malignancy nodule, neck irradiation, } \\
\text { previous surgery, or previous radioactive iodine } \\
\text { treatment }\end{array}$ \\
\hline & $\begin{array}{l}\text { Nodule targeted for HIFU located at least } 3 \mathrm{~mm} \text { from the } \\
\text { trachea, esophagus, recurrent laryngeal nerve, carotid } \\
\text { artery, and skin }\end{array}$ & Any cystic components $\geq 20 \%$ or any large calcifications \\
\hline & $\begin{array}{l}\text { The nodule selected for HIFU treatment was different } \\
\text { from the one indicated for surgery. }\end{array}$ & $\begin{array}{l}\text { Patient unable to maintain a stable position with } \\
\text { hyperextended neck }\end{array}$ \\
\hline \multirow[t]{3}{*}{ Korkusuz et al. (2015) [26] } & Over 18 years old & Malignant nodules \\
\hline & $\begin{array}{l}\text { At least } 1 \text { benign nodule causing neck pain, hoarseness, } \\
\text { swallowing disorders, discomfort, cosmetic concerns, or } \\
\text { thyrotoxicosis }\end{array}$ & $\begin{array}{l}\text { Target nodules too close to the trachea or carotid } \\
\text { arteries }\end{array}$ \\
\hline & Refusing surgery or radioactive iodine treatment & $\begin{array}{l}\text { Patients with a contraindication for HIFU (recurrent } \\
\text { nerve anomalies or target volume) }\end{array}$ \\
\hline \multirow[t]{7}{*}{ Kovatcheva et al. (2015) [27] } & Over 18 years old & $\begin{array}{l}\text { Head and/or neck disease preventing hyperextension } \\
\text { of the neck }\end{array}$ \\
\hline & Presence of 1 or more non-malignant thyroid nodules & $\begin{array}{l}\text { History of thyroid cancer or other malignant tumors in } \\
\text { the neck region }\end{array}$ \\
\hline & $\begin{array}{l}\text { Nodule measuring greater than or equal to } 10 \mathrm{~mm} \text { in } 3 \\
\text { orthogonal dimensions on ultrasonography }\end{array}$ & History of neck irradiation \\
\hline & $<30 \%$ of the targeted nodule comprising a cystic area & $\begin{array}{l}\text { Intranodular macrocalcifications precluding treatment } \\
\text { with HIFU }\end{array}$ \\
\hline & Nodule considered accessible for HIFU & $\begin{array}{l}\text { Nodules next to the posterior margin of the thyroid } \\
\text { lobe with an anteroposterior diameter less than } 15 \mathrm{~mm}\end{array}$ \\
\hline & Normal TSH level & Pregnancy/lactation \\
\hline & No vocal cord immobility on laryngoscopy & $\begin{array}{l}\text { Any contraindications related to moderate intravenous } \\
\text { sedation }\end{array}$ \\
\hline \multirow[t]{7}{*}{ Lang et al. $(2017)[28,29]$} & $\begin{array}{l}\text { Benign cytology and a sonographic pattern with low to } \\
\text { very low suspicion }\end{array}$ & Age $\leq 18$ years old \\
\hline & Nodule causing pressure symptoms & Pregnancy or lactation \\
\hline & All 3 dimensions between 10 and $40 \mathrm{~mm}$ & Indeterminate or malignant nodules \\
\hline & Nodule $\geq 70 \%$ solidity & Intranodular macrocalcifications \\
\hline & Nodule within $5-30 \mathrm{~mm}$ from the skin & History of head and neck irradiation \\
\hline & Normal thyroid function and calcitonin levels & History of non-medullary thyroid carcinoma \\
\hline & & Pre-existing vocal cord palsy \\
\hline
\end{tabular}

HIFU, high-intensity focused ultrasound; TSH, thyroid-stimulating hormone. 
center of the US image.

Under US guidance, the treatment probe is positioned above the skin, superficial to the nodule. The computer (Beamotion version no. TUS 3.2.2, Theraclion) then automatically generates multiple ablation sites on the nodule, with each site measuring $7.3 \mathrm{~mm}$ in thickness and $5 \mathrm{~mm}$ in width (Fig. 1). A HIFU pulse lasting for 8 seconds, followed by 40 seconds of cooling time, is delivered to each ablation site. The length of the cooling time depends on the power of the ablation, with a higher power needing a longer time for cooling (Video clip 1).

\section{Treatment Safety}

The thyroid gland lies near a few vital structures, including the carotid artery, trachea, and recurrent laryngeal nerve [24]. These structures are marked and left unablated. A safety distance is recommended to prevent the treatment beam from ablating these structures: $0.2 \mathrm{~cm}$ for the common carotid arteries, $0.3 \mathrm{~cm}$ for the trachea, and $0.5 \mathrm{~cm}$ for the recurrent laryngeal nerve [24]. However, our recent study suggested that a larger safety distance of up to $1.1 \mathrm{~cm}$ might be necessary to avoid inadvertent injury to the recurrent laryngeal nerve during treatment [30]. A movement detector prevents ablation to unmarked sites by interrupting the power supply. Cooling of the pre-focal tissue is achieved by a plastic balloon placed at the tip of the treatment head, which is filled with a cooling liquid at $10^{\circ} \mathrm{C}$. This prevents any damage to the pre-focal tissues.

\section{Clinical Experience}

Table 2 summarizes the efficacy of HIFU ablation. The first human study of the HIFU ablation of thyroid nodules was conducted by Esnault et al. [25]. That study was conducted on 25 patients, including 5 men and 20 women aged $25-82$ years. All 25 patients underwent HIFU treatment 2 weeks before surgery for nodular goiter. Each specimen was further examined histologically, and the

Table 2. A comparison of pre-ablation nodule volume and treatment efficacy following single-session HIFU ablation

\begin{tabular}{lcll}
\hline \multicolumn{1}{c}{ Study } & No. of nodules treated & \multicolumn{1}{c}{ Pre-ablation volume $(\mathrm{mL})$} & \multicolumn{1}{c}{ Efficacy (\% reduction from baseline) } \\
\hline Esnault et al. (2011) [25] & 22 & Range 0.5-2.6 & Nodules surgically resected and examined histologically after 2 wk \\
Korkusuz et al. (2015) [26] & 9 & Median, 3.5 (0.8-7.7) & Median, 48.8 (11.4-75.0) at 3 mo \\
Kovatcheva et al. (2015) [27] & 20 & Mean $\pm S D, 4.96 \pm 2.79(1.56-9.35)$ & Mean $\pm S D, 48.7 \pm 24.3$ at 6 mo (after single ablation) \\
Lang et al. (2017) [31] & 22 & Mean $\pm S D, 6.98 \pm 4.04(1.68-16.76)$ & Mean $\pm S D, 68.87 \pm 15.27$ at 12 mo (following single ablation) \\
Lang et al. (2017) [23] & 73 & Range 0.6-39.2 & Median \pm SD, 68.3 (22.77-96.5) at 6 mo (following single ablation) \\
\hline
\end{tabular}

HIFU, high-intensity focused ultrasound.

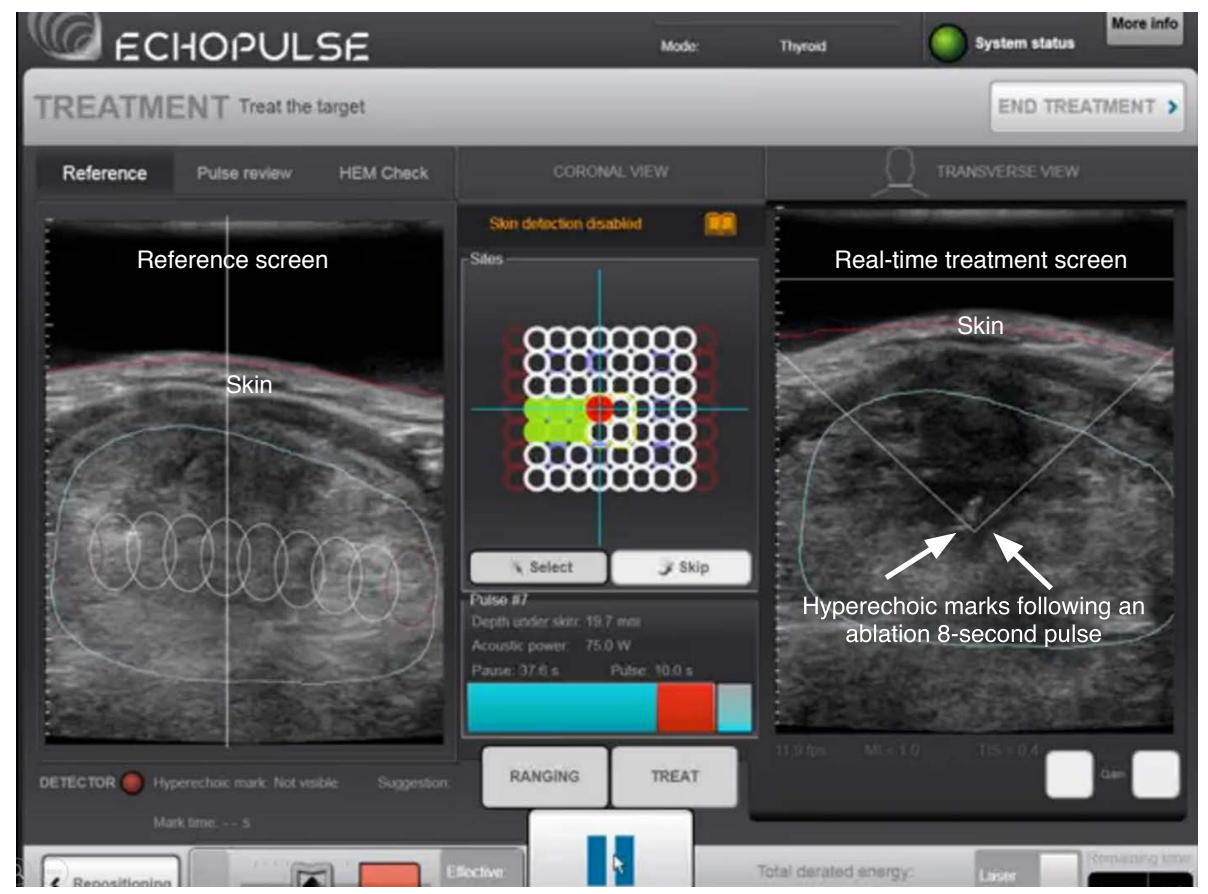

Fig. 1. A treatment image captured immediately after an 8-second treatment pulse. The central panel represents the bird-eye view reconstruction of the nodule. The empty circles represent the non-ablated subunits, while the filled circles represent the ablated subunits. The presence of hyperechoic marks (microbubbles) at the focal point of the high-intensity focused ultrasound beams in the treatment screen should also be noted. 
specific features of lesions caused by HIFU included the presence of coagulative necrosis, multiple fibrotic scars, thrombosis, and a cystic area encircling the lesions [25]. Other non-specific lesions included non-coagulative necrosis, hemorrhage, nodule detachments, cavitations, and cysts [25]. In order to form lesions that were suitable for histological examinations, the depth-independent pulse acoustic energy was gradually increased, from 35 to $94 \mathrm{~J}$. In 10 patients, the thyroid nodule demonstrated clear necrosis following HIFU treatment. In the other cases, cavitation was observed in the nodules, but it was debatable whether the cavitation was caused by HIFU or was due to pre-existing lesions. Nonetheless, if cavitation is considered a HIFU-induced lesion, the degree of nodule destruction ranged from $2 \%$ to $80 \%$. The authors concluded that HIFU treatment was suitable to treat thyroid nodules. The long-term results of HIFU on the thyroid nodules were not discussed in their study since all patients underwent thyroidectomy 2 weeks after HIFU.

Lang et al. [31] conducted a prospective study investigating the first-year efficacy and changes in pressure symptoms and healthrelated quality of life (HRQOL) after HIFU treatment of benign thyroid nodules. A total of 44 patients were included in their study. Of these patients, 22 patients received HIFU treatment, while the other 22 received active surveillance only. Clinical and US examinations, pressure symptom scores, and HRQOL were compared at 3,6, and 12 months. In patients who presented with multiple nodules, only the largest one was ablated. All nodules in HIFU patients showed a reduced volume 1 month after the treatment, with a mean reduction of $22.58 \% \pm 9.23 \%$. Successful ablation, defined as a $>50 \%$ reduction in nodule volume, was achieved in 18 patients (81.8\%) 3 months after the HIFU treatment, with a mean volume reduction of $61.54 \% \pm 16.68 \%$. No further significant reduction in volume was observed at 3,6, and 12 months. Pressure symptoms were significantly reduced in HIFU patients, and significant differences in pain, general health, social functioning, and role emotional were observed between the HIFU group and the active surveillance group. The authors concluded that HIFU was a safe, non-invasive treatment and led to significant improvements over the active surveillance group [31]. A key finding of this study was the relationship between nodule volume and ablation success; small pre-ablation volume was related to a more successful HIFU ablation [31].

Another study conducted by the same group, Lang et al. [23], primarily investigated the treatment of large benign thyroid nodules with HIFU. Seventy-three nodules treated with HIFU and followed up for more than 6 months were selected. Nodule volume was then measured 1 week, 1 month, 3 months, and 6 months after HIFU treatment. At 6 months, nodules with a pre-ablation volume of more than $30 \mathrm{~mL}$ had a mean shrinkage of $48.1 \%$, which was less than the shrinkage observed in those less than $10 \mathrm{~mL}$ and those between 10 and $30 \mathrm{~mL}$ (77.6\% and $67.9 \%$ respectively). The overall median nodule volume reduction was $68.3 \%$ at 6 months after a single HIFU ablation session. The authors concluded that the larger the size of the nodule, the less the extent of nodule shrinkage. A possible explanation for this is an inbuilt limitation of the HIFU device, which can only be used to ablate nodules up to a certain size $(>3.5 \mathrm{~cm}$ to $4.0 \mathrm{~cm})[23]$.

Korkusuz et al. [26] conducted a study regarding the volume reduction of benign thyroid nodules 3 months after a single HIFU treatment. Nine patients were included in the study. The volume of the thyroid nodules was measured before and 3 months after the HIFU therapy. The volume reduction ranged from $11.4 \%$ to $75 \%$, with an overall median nodule volume reduction of $48.8 \%$. It was concluded that the current HIFU method was sufficient to reduce benign nodule volumes in comparison to other non-invasive techniques.

Kovatcheva et al. [27] conducted a prospective study to assess how effective HIFU was for treating benign solid thyroid nodules. Twenty patients with euthyroid nodular goiter were included in the study. US assessments of these patients were conducted at 1 week, 1 month, and 3 months after a single HIFU ablation session. At 1 week, 8 nodules were enlarged, with a mean percentage volume increase of $17.2 \% \pm 9.2 \%$. A mean reduction of $8.7 \% \pm 6.9 \%$ in nodule volume was recorded in the other 12 subjects. A mean volume reduction of $26.3 \% \pm 16.9 \%$ and $38.5 \% \pm 21.6 \%$ was recorded at 1 month and 3 months after HIFU ablation, respectively. Sixteen of the 20 patients had a nodule reduction of more than $30 \%$ and were further followed up. A mean volume reduction of $48.7 \% \pm 24.3 \%$ was measured. It was concluded that a single HIFU treatment was effective for reducing the volume of benign thyroid nodules.

\section{Vocal Cord Palsy}

Since the recurrent laryngeal nerve runs at the back of the thyroid lobe before entering the larynx, vocal cord palsy (VCP) is a potential complication after HIFU ablation. Indeed, VCP occurred not uncommonly following HIFU treatment in earlier series [32,33]. In a recent series of 103 patients who completed single-session HIFU ablation on one side of the thyroid gland, four patients (3.9\%) complained of an immediate voice change after treatment (i.e., on day 0 following treatment) and all were later confirmed to have a completely paralyzed vocal cord by laryngoscopy [30]. Therefore, there was a small but definite risk of VCP following HIFU ablation. The likelihood of this complication was thought to be related to the focused point of the HIFU beam being close to the tracheoesophageal groove where the nerve normally lies [30]. 
Nevertheless, it is worth pointing out that all of these injuries were transient [30].

\section{Changes in Thyroid Function}

Although HIFU treatment is commonly used for ablating benign thyroid nodules, as with all other treatments, it is associated with various side effects, one of which is altered thyroid function following treatment [28]. Therefore, thyroid function tests have commonly been performed before and after HIFU ablation to determine whether HIFU had an effect on thyroid function. Lang et al. [28] analyzed 83 patients who received HIFU treatment for a symptomatic benign thyroid nodule between 2015 and 2016. After excluding patients with suppressed thyroid-stimulating hormone (TSH) levels $(n=6)$, those who received more than 1 treatment $(n=3)$, and those with elevated anti-thyroid auto-antibodies suggestive of lymphocytic thyroiditis $(n=2), 72$ patients were analyzed. Thyroid function was measured on the day before treatment, 1 week after treatment, and 3 and 6 months after the HIFU ablation. Serum TSH dropped at 1 week, from $1.16 \mathrm{mlU} / \mathrm{L}$ at baseline to $0.76 \mathrm{mIU} / \mathrm{L}$, but stayed similar at 3 and 6 months, whereas serum fT4 levels rose at 1 week, from 16.0 to $17.8 \mathrm{pmol} / \mathrm{L}$, but not at 3 or 6 months. Only one patient required thyroxine replacement, but that patient had a previous lobectomy before ablation. In that series, no patients had an autonomously functioning thyroid nodule. Therefore, the authors concluded that altered thyroid function after HIFU treatment was rare and mild. These findings were similar to those of another study by Esnault et al. [25], in which the thyroid function of 22 patients was monitored after HIFU. Other than one patient, no significant changes in TSH, fT3, or fT4 were observed after the HIFU treatment. However, a transient increase in thyroglobulin levels was detected in five patients on the day after HIFU treatment. Euthyroidism was also achieved in eight patients in the study of Korkusuz et al. [26]. Based on the currently available data, we believe that altered thyroid function following single-session HIFU ablation is very rare and is likely to be self-limiting, particularly in patients with no history of thyroidectomy, and would only recommend checking thyroid function once at 1-2 months after HIFU ablation.

\section{Discussion}

Surgical treatment for thyroid nodules is a well-developed technique. However, potential risks such as neck scarring, hoarseness, and the need for thyroid hormone replacement therapy have led to the introduction of non-invasive therapies into clinical practice [29]. Ethanol ablation, LA, microwave ablation, and RFA are the minimally invasive treatments in common use today $[9,10,34]$. Nonetheless, the ever-changing medical world has seen the introduction of newer techniques, such as HIFU. HIFU ablation could be considered a truly non-invasive procedure because it is able to induce irreversible tissue necrosis via thermal ablation beneath the skin without skin puncture or incision [7]. Moreover, because the entire ablation can be programmed, treatment success is thought to be less dependent on the skill of the operator [12]. However, it is associated with complications. These include burning pain [29,32], pain towards the neck and upper back, mild skin redness, and subcutaneous edema $[29,33]$.

Transient VCP appears to be the most common complication following HIFU treatment of thyroid nodules $[30,32,33]$. In a small series of patients, Leenhardt et al. [32] reported this complication in one patient. In a series of 103 patients who underwent HIFU ablation on one side of the thyroid gland, four patients $(3.9 \%)$ were reported to have suffered from unilateral VCP afterwards. Fortunately, all the injuries recovered fully within a period of 6 weeks. In that study, the cause of the injury was further investigated, and it was found that the measurable distance between the focal point of the treatment beam and the tracheoesophageal groove (where the recurrent laryngeal nerve was located) was associated with the risk of this injury. Therefore, the thermal spread of the beam was the likely cause of these temporary nerve injuries [30].

In terms of treatment efficacy, the extent of nodule shrinkage following treatment ranged from $45 \%$ to $50 \%$ in the first 3 to 6 months (Fig. 2) $[23-27,31]$. However, it is worth noting that only two recent studies have reported outcomes for 6 months or longer $[27,31]$. The rest reported outcomes for up to 3 months $[25,26]$. Consistent with experiences with other types of thermal ablation, the treated nodule tended to continually shrink over time, suggesting that the trend of nodule shrinkage would tend to continue for the first 12 months [31]. However, since nodule regrowth can occur following successful LA and RFA (in 5\% of cases) [7], studies with a longer follow-up period are required [25]. The reported efficacies for HIFU were quite variable, but appeared comparable to those for other thermal ablation techniques such as RFA, microwave ablation, and LA [24]. However, it should be pointed out that the baseline nodule characteristics tended to vary across studies, and so a direct comparison between techniques was impossible. Recent studies seemed to report higher rates of efficacy, perhaps related to the use of higher power settings and improved technique.

It has been observed that HIFU ablation of benign thyroid nodules causes a massive release of thyroglobulin into the circulation $[29,35]$. A study conducted by Lang et al. [35] investigated whether the initial rise in thyroglobulin levels was correlated with the success of treatment (nodule shrinkage at 6 months). A sample of 105 patients was selected, and their serum thyroglobulin and anti-thyroglobulin antibodies were measured before HIFU treatment and 4 days after. 


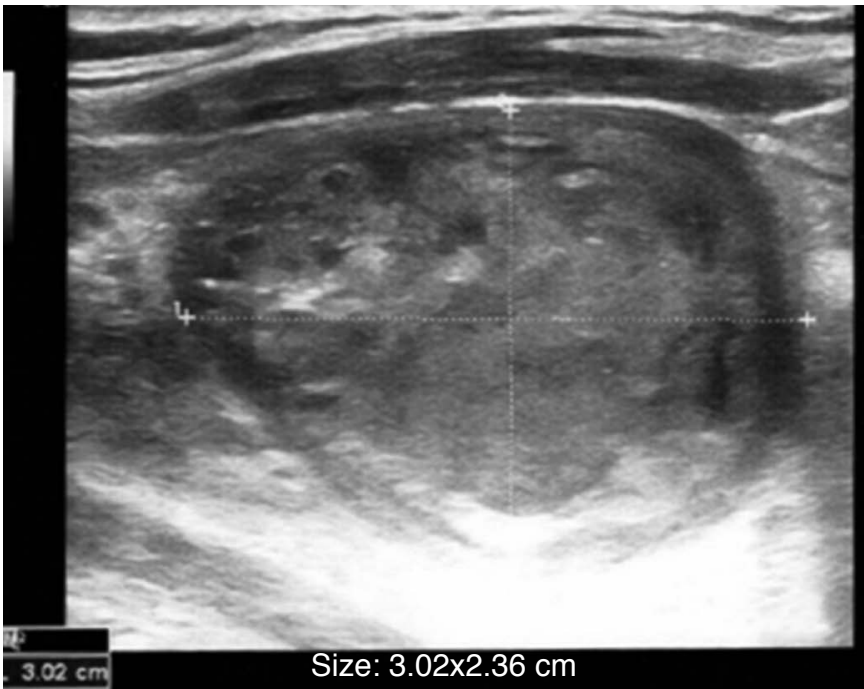

A

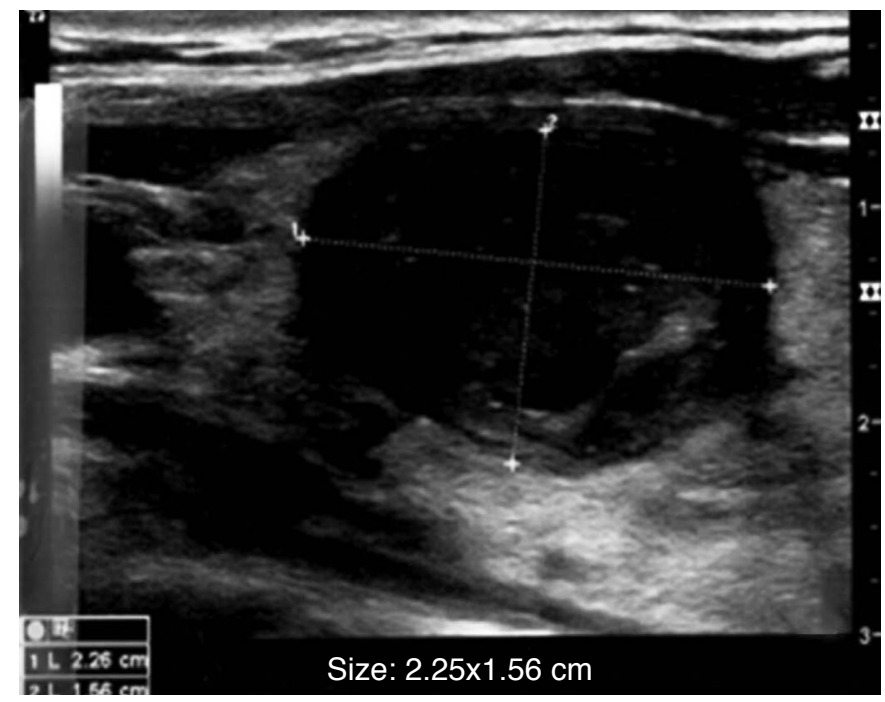

C

Despite a 7-fold increase in the mean thyroglobulin level 4 days after the HIFU ablation, this parameter did not seem to predict the success of HIFU for benign thyroid nodules [35].

Based on our review, several shortcomings related to HIFU ablation are worth highlighting. First, most of the treated nodules were relatively small in terms of size and volume $[10,11]$. On average, using a current US-guided device, a 3-cm thyroid nodule would take approximately 45-60 minutes for complete ablation, while for RFA, microwave ablation, or LA, the procedure would normally take between 15 and 20 minutes. Even though it is possible to increase the power in order to shorten the treatment time, skin burns could become a problem with higher energy, as some energy is absorbed by the skin and subcutaneous tissue during treatment. Second, many unanswered questions remain,

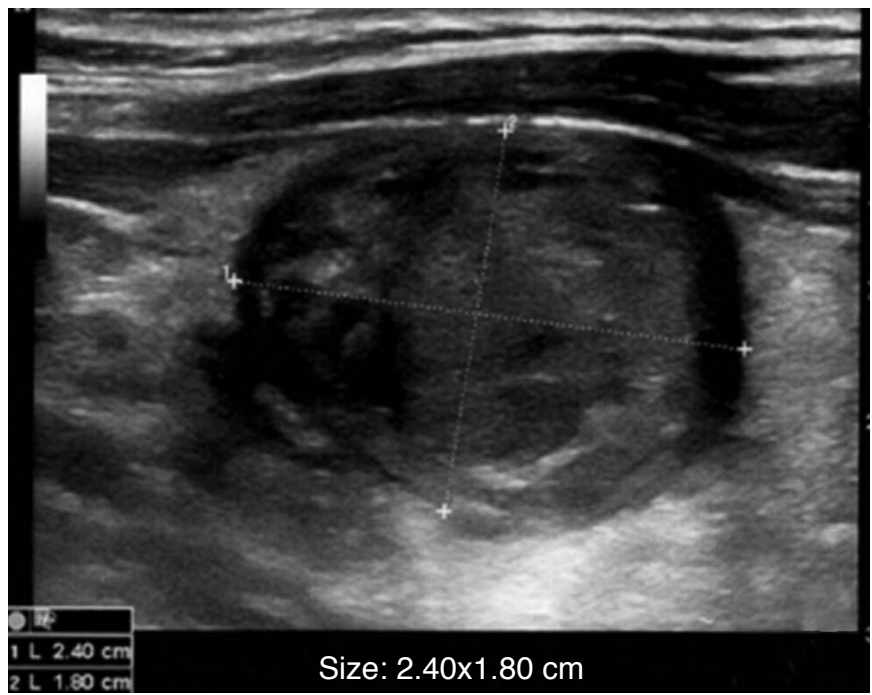

B

Fig. 2. A 37-year-old woman complaining of a growing right thyroid swelling.

A-C. Sagittal ultrasonography of a right solid thyroid nodule obtained before treatment (A) and 3 months (B) and 6 months (C) after high-intensity focused ultrasound treatment are shown. The extent of nodule shrinkage and the echogenic change (from isoechoic to hypoechoic) after treatment should be noted.

since clinical experiences are limited. For example, the longerterm efficacy of ablation remains unknown, although up to $15 \%$ $20 \%$ of nodules can be predicted to show a less-than-adequate response ( $<50 \%$ shrinkage at 6 months). Therefore, it is necessary to validate the factors related to the efficacy of HIFU (or recurrence after HIFU). In other forms of ablation, operator experience, number of treatment sessions, tumor vascularity, and delivered energy have been implicated as factors affecting efficacy [36]. Third, with the currently-available device, treatment pulses can only be applied to a single layer with a maximum treatment depth of $2.8 \mathrm{~cm}$ under the skin. Nodules located in deeper or more posterior parts of the thyroid gland are currently not fully treatable by the current HIFU device. Moreover, the initial starting cost seemed to be much higher than that of other techniques, which was mostly related to the 
start-up cost of the device. Last but not least, HIFU is not a painless procedure, and therefore, deep sedation or even general anesthesia is often necessary to ensure the success of the procedure.

\section{Conclusion}

Despite the relatively limited clinical experiences that have been reported from a handful of specialized centers around the world, our review suggests that single-session HIFU is a safe and efficacious method of treating symptomatic benign thyroid nodules. However, to confirm this finding, a larger-scale, multicenter, prospective trial will be necessary. In terms of the ablation itself, relative to other thermal ablation techniques, there is still much room for improvement in terms of shortening the treatment duration and increasing the range of treatable nodules.

ORCID: Brian H. Lang: http://orcid.org/0000-0002-9362-0086

\section{Conflict of Interest}

No potential conflict of interest relevant to this article was reported.

\section{Supplementary Material}

Video clip 1. This clip shows a typical treatment cycle of a solid thyroid nodule. On the right side of the screen, one can see that the nodule or target was isoechoic in appearance and measured $3.5 \mathrm{~cm}$ in its longest diameter. There was a 35-second coolingdown period before the actual 8-second treatment high-intensity focused ultrasound pulse was administered. During the coolingdown period, the operator may adjust the power of the treatment according to the degree to which the patient tolerates it and the presence of hyperechoic marks on the screen. In the latter part of the clip, following the 8-second treatment pulse, the treatment head moved to a different region of the nodule. This cycle continued until the planned layer of the nodule had been completely ablated. A typical session comprises 50 to 70 treatment cycles, lasting for 40 50 minutes (https://doi.org/10.14366/usg.17057.v001).

\section{References}

1. Gharib H, Papini E, Garber JR, Duick DS, Harrell RM, Hegedus L, et al. American Association of Clinical Endocrinologists, American College of Endocrinology, and Associazione Medici Endocrinologi medical guidelines for clinical practice for the diagnosis and management of thyroid nodules: 2016 update. Endocr Pract 2016;22:622-639.

2. Haugen BR, Alexander EK, Bible KC, Doherty GM, Mandel SJ, Nikiforov YE, et al. 2015 American Thyroid Association management guidelines for adult patients with thyroid nodules and differentiated thyroid cancer: the American Thyroid Association Guidelines Task Force on Thyroid Nodules and Differentiated Thyroid Cancer. Thyroid 2016:26:1-133.

3. Lee L, Mitmaker EJ, Chabot JA, Lee JA, Kuo JH. Cost-effectiveness of diagnostic lobectomy versus observation for thyroid nodules $>4$ cm. Thyroid 2016;26:271-279.

4. Bergenfelz A, Jansson S, Kristoffersson A, Martensson H, Reihner E, Wallin $\mathrm{G}$, et al. Complications to thyroid surgery: results as reported in a database from a multicenter audit comprising 3,660 patients. Langenbecks Arch Surg 2008;393:667-673.

5. Gharib H, Hegedus L, Pacella CM, Baek JH, Papini E. Clinical review: nonsurgical, image-guided, minimally invasive therapy for thyroid nodules. J Clin Endocrinol Metab 2013;98:3949-3957.

6. Korkusuz Y, Groner D, Raczynski N, Relin O, Kingeter Y, Grunwald $F$, et al. Thermal ablation of thyroid nodules: are radiofrequency ablation, microwave ablation and high intensity focused ultrasound equally safe and effective methods? Eur Radiol 2018;28:929-935.

7. Papini E, Rago T, Gambelunghe G, Valcavi R, Bizzarri G, Vitti P, et al. Long-term efficacy of ultrasound-guided laser ablation for benign solid thyroid nodules. Results of a three-year multicenter prospective randomized trial. J Clin Endocrinol Metab 2014;99:3653-3659.

8. Sung JY, Baek JH, Kim KS, Lee D, Yoo H, Kim JK, et al. Single-session treatment of benign cystic thyroid nodules with ethanol versus radiofrequency ablation: a prospective randomized study. Radiology 2013;269:293-300.

9. Wong KP, Lang BH. Use of radiofrequency ablation in benign thyroid nodules: a literature review and updates. Int J Endocrinol 2013;2013:428363.

10. Deandrea M, Sung JY, Limone P, Mormile A, Garino F, Ragazzoni F, et al. Efficacy and safety of radiofrequency ablation versus observation for nonfunctioning benign thyroid nodules: a randomized controlled international collaborative trial. Thyroid 2015;25:890-896.

11. Esnault O, Franc B, Monteil JP, Chapelon JY. High-intensity focused ultrasound for localized thyroid-tissue ablation: preliminary experimental animal study. Thyroid 2004;14:1072-1076.

12. Hong K, Georgiades C. Radiofrequency ablation: mechanism of action and devices. J Vasc Interv Radiol 2010;21 (8 Suppl):S179-S186.

13. Zhou YF. High intensity focused ultrasound in clinical tumor ablation. World J Clin Oncol 2011;2:8-27.

14. Hill CR, ter Haar GR. Review article: high intensity focused ultrasound: potential for cancer treatment. Br J Radiol 1995;68:1296-1303.

15. Kim YS, Rhim H, Choi MJ, Lim HK, Choi D. High-intensity focused ultrasound therapy: an overview for radiologists. Korean J Radiol 2008;9:291-302.

16. Ashokkumar M. The characterization of acoustic cavitation bubbles: an overview. Ultrason Sonochem 2011;18:864-872.

17. Dalecki D. Mechanical bioeffects of ultrasound. Annu Rev Biomed 
Eng 2004;6:229-248.

18. Korkusuz H, Fehre N, Sennert M, Happel C, Grunwald F. Early assessment of high-intensity focused ultrasound treatment of benign thyroid nodules by scintigraphic means. J Ther Ultrasound 2014;2:18.

19. Cirincione R, Di Maggio FM, Forte GI, Minafra L, Bravata V, Castiglia $L$, et al. High-intensity focused ultrasound- and radiation therapy-induced immuno-modulation: comparison and potential opportunities. Ultrasound Med Biol 2017;43:398-411.

20. Na DG, Lee JH, Jung SL, Kim JH, Sung JY, Shin JH, et al. Radiofrequency ablation of benign thyroid nodules and recurrent thyroid cancers: consensus statement and recommendations. Korean J Radiol 2012;13:117-125.

21. Baek JH. Current status of core needle biopsy of the thyroid. Ultrasonography 2017;36:83-85.

22. Na DG, Baek JH, Jung SL, Kim JH, Sung JY, Kim KS, et al. Core needle biopsy of the thyroid: 2016 Consensus Statement and Recommendations from Korean Society of Thyroid Radiology. Korean J Radiol 2017;18:217-237.

23. Lang BH, Woo YC, Chiu KW. Single-session high-intensity focused ultrasound treatment in large-sized benign thyroid nodules. Thyroid 2017;27:714-721.

24. Lang BH, Wu AL. High intensity focused ultrasound (HIFU) ablation of benign thyroid nodules: a systematic review. J Ther Ultrasound 2017;5:11.

25. Esnault O, Franc B, Menegaux F, Rouxel A, De Kerviler E, Bourrier $P_{\text {, }}$ et al. High-intensity focused ultrasound ablation of thyroid nodules: first human feasibility study. Thyroid 2011;21:965-973.

26. Korkusuz H, Fehre N, Sennert M, Happel C, Grunwald F. Volume reduction of benign thyroid nodules 3 months after a single treatment with high-intensity focused ultrasound (HIFU). J Ther Ultrasound 2015;3:4.

27. Kovatcheva RD, Vlahov JD, Stoinov JI, Zaletel K. Benign solid thyroid nodules: US-guided high-intensity focused ultrasound ablation- initial clinical outcomes. Radiology 2015;276:597-605.

28. Lang BH, Woo YC, Chiu KW. High-intensity focused ablation (HIFU) of single benign thyroid nodule rarely alters underlying thyroid function. Int J Hyperthermia 2017;33:875-881.

29. Lang BH, Wong CK, Ma EP. Single-session high intensity focussed ablation (HIFU) versus open cervical hemithyroidectomy for benign thyroid nodule: analysis on early efficacy, safety and voice quality. Int J Hyperthermia 2017;33:868-874.

30. Lang BH, Woo YC, Chiu KW. Vocal cord paresis following singlesession high intensity focused ablation (HIFU) treatment of benign thyroid nodules: incidence and risk factors. Int J Hyperthermia 2017;33:888-894.

31. Lang BH, Woo YC, Wong CK. High-intensity focused ultrasound for treatment of symptomatic benign thyroid nodules: a prospective study. Radiology 2017;284:897-906.

32. Leenhardt L, Rouxel A, Menegaux F, Esnault O. An open-label, randomized, controlled study of the effectiveness and safety of a high intensity focused ultrasound device compared with observation in patients with non-malignant cold thyroid nodules. Endocr Abstr 2013;32:P1013.

33. Kovatcheva RD, Zaletel K. High-intensity focused ultrasound for thyroid nodule ablation: the evidence to date. Rep Med Imaging 2017;10:9-16.

34. Papini E, Gugliemi R, Pacella CM. Laser, radiofrequency, and ethanol ablation for the management of thyroid nodules. Curr Opin Endocrinol Diabetes Obes 2016;23:400-406.

35. Lang BH, Woo YC, Chiu KW. The percentage of serum thyroglobulin rise in the first-week did not predict the eventual success of highintensity focused ablation (HIFU) for benign thyroid nodules. Int J Hyperthermia 2017;33:882-887.

36. Ahn HS, Kim SJ, Park SH, Seo M. Radiofrequency ablation of benign thyroid nodules: evaluation of the treatment efficacy using ultrasonography. Ultrasonography 2016;35:244-252. 